\title{
Remoción de cromo hexavalente por la cascara de Plátano (Musa cavendishii)
}

\author{
Leticia Torres ${ }^{\mathrm{a}}$, Juan F. Cárdenas ${ }^{\mathrm{a}}$, María de Guadalupe Moctezuma ${ }^{\mathrm{a}}$, Víctor Manuel Martínez ${ }^{\mathrm{b}}$ y \\ Ismael Acosta ${ }^{a}$ * \\ ${ }^{a}$ Laboratorio de Micología Experimental. CIEP. Facultad de Ciencias Químicas. Universidad Autónoma de San Luís Potosí. Av. Dr. \\ Manuel Nava No. 6. Zona Universitaria. C.P. 78320. San Luis Potosí, S.L.P. México. \\ ${ }^{b}$ Área Académica de Medicina Veterinaria y Zootecnia. Instituto de Ciencias Agropecuarias. Universidad Autónoma del Estado de \\ Hidalgo. \\ *E-mail: iacosta@uaslp.mx
}

Recibido 16 de noviembre de 2012, Aceptado 12 de diciembre de 2012

\begin{abstract}
Resumen
En este trabajo, se analizó la capacidad de remoción de Cromo (VI) en solución por cáscara de Plátano, determinando la concentración del metal por el método de la Difenilcarbazida, encontrando que la remoción total del metal (50 mg/L) mayor ocurre a los 60 minutos, a $\mathrm{pH}$ de 1.0 y $28^{\circ} \mathrm{C}$. Con respecto a la temperatura, la más alta remoción se observó a 60 ${ }^{\circ} \mathrm{C}$, pues a los 40 minutos, el metal $(1 \mathrm{~g} / \mathrm{L})$ se remueve completamente. En las concentraciones de $\mathrm{Cr}$ (VI) analizadas, la cáscara de plátano, mostró gran capacidad de remoción; además, después de 40 minutos de incubación, la biomasa estudiada disminuye $1.0 \mathrm{~g}$ de $\mathrm{Cr}(\mathrm{VI})$ con la producción simultánea de $\mathrm{Cr}(\mathrm{III})$, por lo que puede utilizarse para eliminarlo de aguas residuales industriales.
\end{abstract}

Palabras clave: Cromo (VI), Difenilcarbazida, Remoción, Cáscara de plátano, Biorremediación

\section{Introducción}

Debido a las actividades industriales, como la producción de acero, minería, cemento y curtido de pieles, ciertas zonas de la República Mexicana, tienen altos niveles de cromo en suelo y agua [1]. El uso de lodos de aguas negras o de fertilizantes con diferentes concentraciones del catión, en algunas prácticas agronómicas, son otros de los factores contribuyentes a la contaminación ambiental por el metal. Pese a que este metal es un elemento esencial para hombres y animales, niveles elevados del mismo ( $15 \mu \mathrm{g}$ en agua de ríos y $0.10 \mathrm{mg} / \mathrm{L}$ en agua potable) resultan tóxicos en los seres vivos. Particularmente, el $\mathrm{Cr}(\mathrm{VI})$ tiene efectos carcinogénicos y mutagénicos en humanos, animales y bacterias [1]. En las aguas residuales, el $\mathrm{Cr}(\mathrm{VI})$, se encuentra en solución como $\mathrm{CrO}_{4}^{2-}[2]$, puede removérsele por reducción, por precipitación química, por adsorción y por intercambio iónico [3]. Actualmente, el proceso más utilizado es la adición de un agente reductor que convierta el $\mathrm{Cr}(\mathrm{VI})$ a $\mathrm{Cr}(\mathrm{III})$ y posteriormente se le precipita con soluciones básicas a $\mathrm{Cr}(\mathrm{OH})_{3}$ [3].

Recientemente, se ha analizado el uso de metodologías alternativas, como la remoción y/o reducción de $\mathrm{Cr}(\mathrm{VI})$ a $\mathrm{Cr}(\mathrm{III})$ por bacterias, algas, levaduras y hongos [3]. Por otro lado, también se han utilizado materiales de desecho, como residuos industriales agrícolas o urbanos para la eliminación y/o recuperación de metales pesados de efluentes industriales contaminados, entre los que se encuentran: residuos de manzana, corteza de árbol, cáscara de avellana, cáscara de naranja y tamarindo [4] con resultados altamente satisfactorios. Por lo anterior, es de gran interés analizar otros materiales de desecho y por lo tanto económicos, para tratar de eliminar este metal de aguas y suelos contaminados, así como la biorremediación de los mismos. Por lo que el objetivo de este trabajo fue estudiar la remoción de Cromo (VI) por la cáscara de Plátano (Musa cavendishii).

\section{Parte experimental}

Se utilizó la biomasa celular de cáscara de plátano obtenida de diferentes mercados sobre ruedas de la ciudad de San Luis Potosí, S.L.P., México, en el período mayo-junio de 2012. Ésta, se lavó con agua tridesionizada durante $72 \mathrm{~h}$, y se calentó a ebullición $60 \mathrm{~min}$, para remover el polvo y los componentes orgánicos adheridos, se volvió a lavar con agua tridesionizada $24 \mathrm{~h}$, se secó $\left(60^{\circ} \mathrm{C}\right.$, $24 \mathrm{~h}$ ) en estufa bacteriológica, se molió hasta la obtención de un polvo fino, y se guardó hasta su uso, en frascos de vidrio ámbar a temperatura ambiente.

\subsection{Soluciones de Cromo (VI)}

Se trabajó con $100 \mathrm{~mL}$ de una solución de 50 $\mathrm{mg} / \mathrm{L}$ de concentración de $\mathrm{Cr}(\mathrm{VI})$ obtenida por dilución de una solución patrón de $71.86 \mathrm{mg} / \mathrm{L}$ preparada en agua tridesionizada a partir de $\mathrm{K}_{2} \mathrm{CrO}_{4}$. Se ajustó el $\mathrm{pH}$ de la dilución a analizar 
con $\mathrm{H}_{2} \mathrm{SO}_{4} 1 \mathrm{M}$ y/o NaOH $1 \mathrm{M}$, antes de adicionarla a la biomasa celular.

\subsection{Estudios de bioadsorción}

$1 \mathrm{~g}$ de biomasa celular se mezcló con $100 \mathrm{~mL}$ de una solución de $50 \mathrm{mg} / \mathrm{L}$ de concentración del metal (a diferentes $\mathrm{pH}$ y $28{ }^{\circ} \mathrm{C}$ ) y se incubaron con agitación constante $(100 \mathrm{rpm})$ durante 24 horas. A diferentes tiempos se tomaron alícuotas de $5 \mathrm{~mL}$ cada una, se centrifugaron a $3000 \mathrm{rpm}$ ( $5 \mathrm{~min})$, y al sobrenadante respectivo se le determinó la concentración de $\mathrm{Cr}(\mathrm{VI})$, utilizando el método colorimétrico de la difenilcarbazida [5].

\section{Resultados y discusión}

En este trabajo, se encontró que la biomasa de la cáscara de Plátano remueve eficientemente, y a tiempos cortos, $50 \mathrm{mg} / \mathrm{L}$ de Cromo (VI) en solución, pues a los $60 \mathrm{~min}, 1 \mathrm{~g}$ de biomasa remueve el $100 \%$ del metal como se observa en la Figura 1. La literatura, Pérez y cols., [6] reportan un tiempo óptimo de remoción de plomo de 60 min utilizando cáscara de naranja, y de $2 \mathrm{~h}$ para la remoción de Cromo (VI) por la corteza de eucalipto [7]. Cabe mencionar que el tiempo de remoción óptimo encontrado en este trabajo es menor a lo reportado por Agarwal y cols., [8], y Popuri y cols., [9] quienes establecen tiempos de 180 y 120 min para las semillas y la cáscara de tamarindo tratada con ácido oxálico, respectivamente. Cambios en la permeabilidad, de origen desconocido, podrían explicar en parte las diferencias encontradas en el tiempo de incubación, proporcionando mayor o menor exposición de los grupos funcionales de la pared celular de la biomasa [10].

Con respecto a la influencia del $\mathrm{pH}$ inicial sobre la eficiencia de remoción, se encontró que la mayor actividad se evidenció a $\mathrm{pH} 1.0+/-0.2$, pues a los 60 min se remueve el $100 \%$ del metal (Figura 1), lo cual coincide con algunos reportes de la literatura $[11,12]$. Para las biomasas naturales, la mayoría de los autores reportan un $\mathrm{pH}$ óptimo de 2.0 como: semillas de tamarindo [8], la corteza de eucalipto [6]; bagazo y pulpa de caña de azúcar [13], fibras de coco [14] y lana [15], y un $\mathrm{pH}$ de 3.0 para la cáscara de tamarindo tratada con ácido oxálico [9]. El Cromo (VI) se encuentra como $\mathrm{HCrO}_{4}^{-}, \mathrm{Cr}_{2} \mathrm{O}_{7}{ }^{2-}$, $\mathrm{CrO}_{4}{ }^{2-}, \mathrm{Cr}_{4} \mathrm{O}_{13}{ }^{2-}, \mathrm{Cr}_{3} \mathrm{O}_{10}{ }^{2-}$ [16]. Una baja en el $\mathrm{pH}$ causa la protonación de la superficie del adsorbente, lo que induce una fuerte atracción por los iones Cromo (VI) de la solución cargados negativamente, por lo que la bioadsorción incrementa al aumentar la acidez de la solución. Sin embargo, cuando el pH aumenta, se incrementa la concentración de iones $\mathrm{OH}-$, induciendo cambios en la superficie del adsorbente, impidiendo la bioadsorción de los iones Cromo (VI) cargados negativamente, lo cual disminuye la adsorción del metal a esos valores de $\mathrm{pH}$ [17].

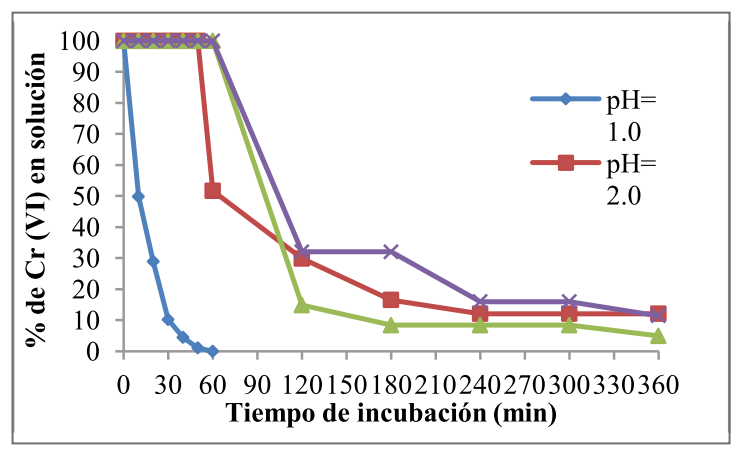

Figura 1. Efecto de diferentes $\mathrm{pH}$ sobre la remoción de $50 \mathrm{mg} / \mathrm{L}$ de $\mathrm{Cr}(\mathrm{VI})$ en solución. $1 \mathrm{~g}$ de biomasa, $28^{\circ} \mathrm{C}$, $100 \mathrm{rpm}$ de agitación constante.

Con respecto a la temperatura, la más alta remoción se observó a $60^{\circ} \mathrm{C}$, pues a los 20 min se remueve el $100 \%$ de Cromo (VI) en solución (50 $\mathrm{mg} / \mathrm{L}$ ) como se observa en la Figura 2, resultados que son coincidentes con los de Acosta-Rodríguez y cols., [11, 12] para las cáscaras de litchi y naranja con un $100 \%$ de remoción a los 6 y $10 \mathrm{~min}$., Agarwal y cols., [8], con un $98 \%$ a $58^{\circ} \mathrm{C}$ y 180 min., y con los de Leyva et al. [18] para la remoción de cadmio (II) con olote de maíz $\left(40{ }^{\circ} \mathrm{C}\right.$ y 5 días). El incremento en la temperatura aumenta la velocidad de remoción de Cromo (VI) y disminuye el tiempo de contacto requerido para la completa remoción del metal, por incrementar la exposición de los grupos funcionales que reaccionan con el mismo [19].

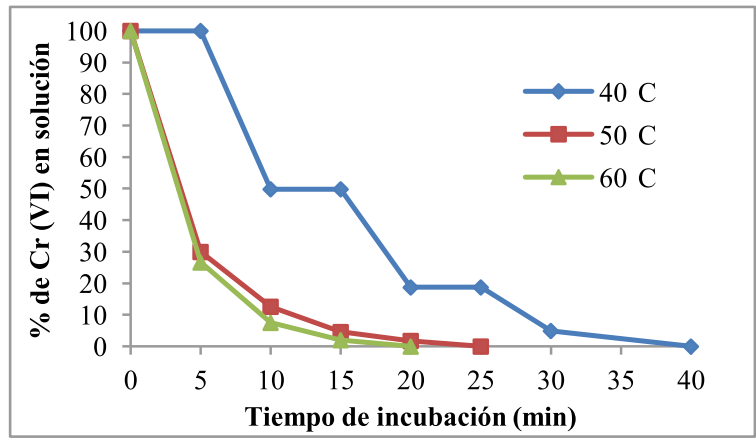

Figura 2. Efecto de la temperatura de incubación sobre la remoción de $50 \mathrm{mg} / \mathrm{L}$ de $\mathrm{Cr}(\mathrm{VI})$ en solución. $1 \mathrm{~g}$ de biomasa, $100 \mathrm{rpm}$ de agitación constante, $\mathrm{pH}=1.0$.

También se encontró que la concentración del metal no influye en la remoción del mismo, pues 200 y $1000 \mathrm{mg}$ de $\mathrm{Cr}(\mathrm{VI})$ se eliminan a los $40 \mathrm{~min}$ a $60{ }^{\circ} \mathrm{C}$ como se observa en la Figura 3, es muy similar a otros reportes de la literatura [12]. 
Algunos autores [20], sostienen que la cantidad de metal eliminado por las biomasas de diferentes microorganismos, tales como Mucor hiemalis y Rhizopus nigricans aumenta en proporción directa con el incremento de la concentración del ión metálico en solución. Con respecto a las otras biomasas utilizadas, la mayoría de los autores reportan menores eficiencias de remoción del metal, por ejemplo: $45 \mathrm{mg} / \mathrm{L}$ por la corteza de eucalipto [7]; 13.4 y $17.2 \mathrm{mg} / \mathrm{L}$ por bagazo y pulpa de caña de azúcar [13], $29 \mathrm{mg} / \mathrm{L}$ por fibra de coco [14], $8.66 \mathrm{mg} / \mathrm{L}$ por la lana [15]. Al aumentar la cantidad de biomasa, también se incrementa la remoción de Cromo (VI) en solución como se observa en la Figura 4, pues $5 \mathrm{~g}$ de la cáscara remueven el $100 \%$ del metal a los $25 \mathrm{~min}$, a $28{ }^{\circ} \mathrm{C}$, debido a que hay más sitios de bioadsorción del metal, ya que la cantidad de bioadsorbente añadido determina el número de sitios de unión disponibles para la bioadsorción del metal [3]. Resultados similares se han reportado para la cáscaras de litchi y naranja [11, 12], $R$. nigricans, aunque éste último con $10 \mathrm{~g}$ de biomasa [20], pero son diferentes a lo reportado por Zubair y cols., [21], para la biomasa de los desechos de la mandarina (gabazo), quienes reportan una concentración óptima de biomasa de $100 \mathrm{mg} / \mathrm{L}$.

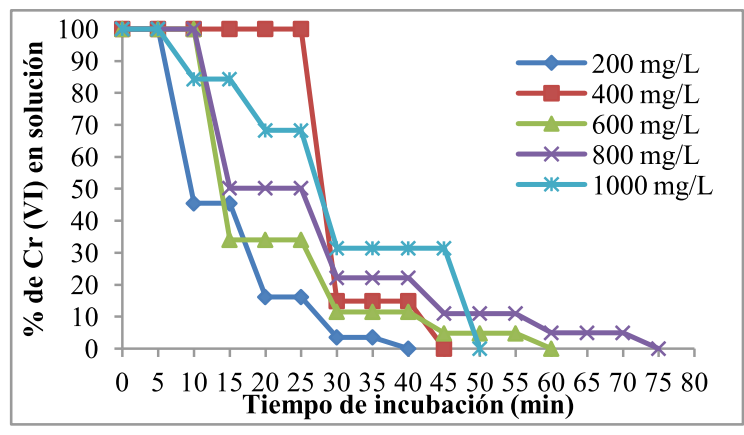

Figura 3. Efecto de la concentración de $\mathrm{Cr}$ (VI) sobre la remoción del mismo. $50 \mathrm{mg} / \mathrm{L}, 60^{\circ} \mathrm{C}, 100 \mathrm{rpm}$ de agitación constante, $\mathrm{pH}=1.0$.

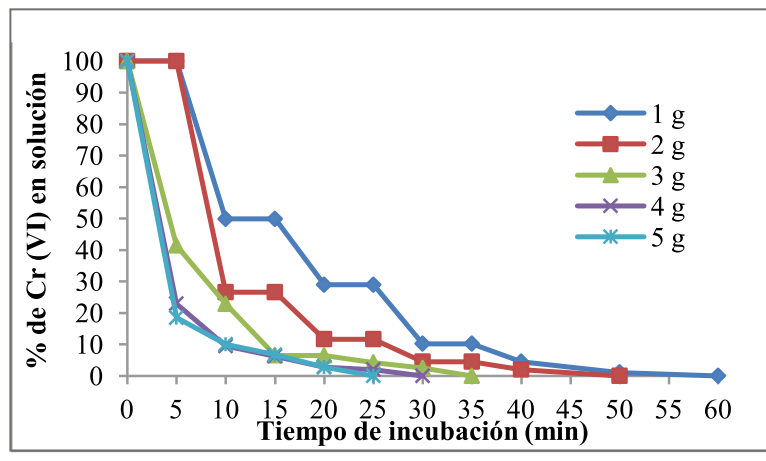

Figura 4. Efecto de la concentración de la biomasa sobre la remoción de $50 \mathrm{mg} / \mathrm{L}$ de $\mathrm{Cr}(\mathrm{VI})$ en solución. $28^{\circ} \mathrm{C}$, $100 \mathrm{rpm}$ de agitación constante, $\mathrm{pH}=1.0$.
Se analizó la capacidad de la biomasa de la cáscara de Plátano para disminuir la concentración inicial de Cromo (VI) $(1.0 \mathrm{~g} / \mathrm{L})$ y la producción de Cromo (III) en solución. En la Figura 5 se observa una gran disminución de los niveles de Cromo (VI), con la producción concomitante de Cromo (III), (indicado por la desaparición del color amarillo en los matraces por la presencia de Cromo (VI) y la formación de un color azul-verdoso con un precipitado blanco, que indica la transformación a Cromo (III), y su determinación por Cromazurol S, (datos no mostrados). Después de $40 \mathrm{~min}$., de incubación, la biomasa disminuye la concentración inicial del metal, hasta niveles indetectables, sin cambios significativos en la concentración de Cromo total, la cual permanece constante en el control de agua tridesionizada. Lo anterior indica que esta biomasa es capaz de reducir el metal en la solución de trabajo suplementada con cromato. La capacidad de reducir Cromo (VI) se ha reportado ampliamente en la literatura en microorganismos que incluyen levaduras y hongos como C. maltosa [22] (Ramírez et al., 2004), Candida sp FGSFEP [23], (Guillén et al., 2008) Aureobasidium pullulans [24](Fukuda et al., 2008), y para las cáscaras de litchi y naranja $[11,12]$.

\section{Conclusiones}

La biomasa analizada tiene la capacidad de remover eficientemente $\mathrm{Cr}(\mathrm{VI})$ en solución, y es por esta característica que puede ser usada en la descontaminación de efluentes industriales conteniendo dicho metal, por lo que la aplicación de esta tecnología presenta mucho potencial para la eliminación de éste; además de que la biomasa es natural, fácil de transportar, fácil de obtener en grandes cantidades y es considerada un material de desecho.

\section{Referencias}

1. Viti, C.; Pace, A.; Giovenneti, L. Curr. Microbiol. 2003, 46, $1-5$

2. Cotton, F.A.; Wilkinson, G. Advanced Inorganic Chemistry. 4a. ed.; Chichester: U.K., 1980, 121.

3. Cervantes, C.; Campos, García, J.; Devars, S.; Gutiérrez, Corona, J.F.; Loza-Tavera, H.; Torres-Guzmán, J.C.; Moreno-Sánchez, R. FEMS Microbiol. Rev. 2001, 25, 333347

4. Verma, A.; Chakraborty, S.; Basu, J.K. Sep. Purif. Technol. 2006, 50, 336-341

5. Greenberg, A.; Clesceri, L.; Eaton, A. Standard Methods for the Examination of Water and Wastewater, 18a. ed.; American Public Health Association, Washington, D.C., 2002, 3.58-3.60

6. Pérez, A.B.; Meseguer Zapata, V.; Ortuño, J.F.; Aguilar, M.; Sáez, J.; Lloréns, M. J. Hazard. Mat. 2007, 139(1), 122-131

7. Sarin, V.; Pant, K.K. Biores. Technol. 2006, 97, 15-20

8. Agarwal, G.S.; Kumar, H.; Chaudar, S. Bioresour. Technol. 2006, 949-956 
9. Popuri, R.S.; Jammala, A.; Naga Suresh, K.; Abuburi, K. J. Biotech. 2007, 10(3), 358-367

10. Kratochvil, D.; Volesky, B. TIBTECH. 1998, 16, 291-300

11. Acosta-Rodríguez, I.; Martínez-Pérez, R.; CardenasGonzalez, J.F.; Moctezuma-Zarate, M.G.; Martinez-Juarez, V.M. J. Biochem. Biotech. 2012, 8, (1), 7-13

12. Acosta-Rodríguez, I., González Sánchez, H.M.; MoctezumaZárate, M.G.; Cárdenas González, J.F.; Martínez Juárez, V.M: Tlatemoani 2012, 9, 1-17

13. Sharma, D.C.; Forster, C.F. Biores. Technol. 1994, 47, $257-$ 264

14. Huang, C.P.; Wu, M.H. Water Res. 1977, 11, 673-679

15. Dakiki, M.; Khamis, M.; Manassra, A.; Mereb, M. $A d v$. Environ. Res. 2002, 6, 533-540

16. Rollinson, C.L. Chromium, molybdenum and tungsten, in: T. Dickson (ed), Comprehensive Organic Chemistry, 3a. ed. Pergamon Press, Oxford, UK, 1973, 691-694

17. Gadd, G.M.; Griffiths, A.J. Trans. Brit. Mycol. Soc. 1980, 74(2), 387-392

18. Leyva, R.; Bernal, L.A.; Acosta, I. Sep. Pur. Technol. 2005, $45,41-49$

19. Wittbrodt, P.R.; Palmer, C.D. Environ. Science Technol. 1996, 30(8), 2470-2477

20. Bai, R.S.; Abraham, T.E. Biores. Technol. 2001, 79, 73-81

21. Zubair, A.; Bhatti, H.N.; Hanif, M.A.; Shafqat, F. Wat. Air and Soil Poll. 2008, 191, 305-318

22. Ramírez, R.; Calvo, C.; Avila, M.; Lappe, P.; Ulloa, M.; Vázquez, R.; Gutiérrez-Corona, J.F. Ant. Van Leeuwen. 2004, 85, 63-68

23. Guillen, F.M.; Morales, L.; Morales, J.; Hernández, C.H.; Cristiani, E. J. Ind. Microbiol. Biotechnol. 2008, 35, 1277 1287

24. Fukuda, T.; Ishino, Y.; Ogawa, A.; Tsutsumi, K.; Morita, H. J. Gen. Appl. Microbiol. 2008, 54(5), 295 $₫ 300$. 